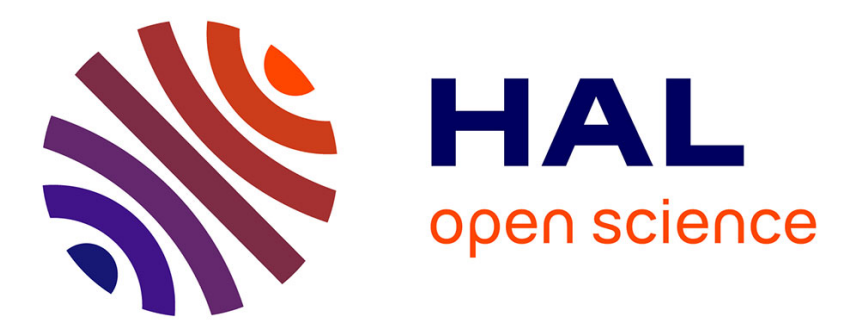

\title{
A Comparison between CG and PSO Algorithms for the Design of a PM Motor for Fuel Cell Ancillaries
}

\author{
Frédéric Dubas, Ali Sari, Daniel Hissel, Christophe Espanet
}

\section{To cite this version:}

Frédéric Dubas, Ali Sari, Daniel Hissel, Christophe Espanet. A Comparison between CG and PSO Algorithms for the Design of a PM Motor for Fuel Cell Ancillaries. IEEE Vehicle Power and Propulsion Conference (VPPC), Sep 2008, Harbin, China. pp.01-07. hal-00322516

\section{HAL Id: hal-00322516 https://hal.science/hal-00322516}

Submitted on 17 Sep 2008

HAL is a multi-disciplinary open access archive for the deposit and dissemination of scientific research documents, whether they are published or not. The documents may come from teaching and research institutions in France or abroad, or from public or private research centers.
L'archive ouverte pluridisciplinaire HAL, est destinée au dépôt et à la diffusion de documents scientifiques de niveau recherche, publiés ou non, émanant des établissements d'enseignement et de recherche français ou étrangers, des laboratoires publics ou privés. 


\title{
A Comparison between CG and PSO Algorithms for the Design of a PM Motor for Fuel Cell Ancillaries
}

\author{
F. Dubas, A. Sari, D. Hissel, and C. Espanet \\ University of Franche-Comte (UFC), FEMTO-ST Institute, CNRS UMR 6174, ENISYS Department, FC-LAB Institute, \\ 13 Rue Thierry MIEG, F90010 Belfort. \\ Email: FDubas@gmail.com, ali.sari@femto-st.fr, daniel.hissel@univ-fcomte.fr and christophe.espanet@univ-fcomte.fr \\ Phone: +33 (0)3 84583634 - Fax: +33 (0)384583636
}

\begin{abstract}
This paper deals with the design of a $500 \mathrm{~W}$ permanent magnet (PM) machine used to drive the air-compressor of a $5 \mathrm{~kW}$ fuel cell (FC). The authors focus on the optimization of the PM motor efficiency/mass/efficiency-mass in order to minimize the energy consumption of the air-compressor which can represent up to $30 \%$ of the electrical energy delivered by the FC. The aim of this paper is to compare two types of optimization algorithm: Conjugate Gradient (CG) and Particle Swarm Optimization (PSO).
\end{abstract}

\section{INTRODUCTION}

In the last decade, problems of the greenhouse gas emissions control and hydrocarbon energy resources exhaustion, started again researches on FC in many fields, such as transport, stationary power generation and portable applications [1]. Among these fields, the surface transports, that strongly use oil-based hydrocarbons, is one of the sectors generating the strongest greenhouse gas emissions. On the opposite, a FC directly supplied by hydrogen does not generate locally any environmental pollution. From this point of view, it is an interesting alternative to the internal combustion engine. A proton exchange membrane (PEM) FC, which is the most commonly used FC in the transport area, is an electrochemical converter which makes it possible to obtain electrical power and thermal energy by an oxydo-reduction reaction starting from a fuel (generally hydrogen) [2], [3], [4]. The energetic efficiency of FC itself is relatively high compared to other more conventional technologies (PEM FC efficiency about $50 \%$ and heat engine efficiency about 32\%). But its output power decreases due to the ancillaries that are necessary to the correct operation of the FC [Fig. 1.]: fuel (hydrogen) and fuel oxidizer (oxygen) supply, humidification, cooling, electric converter,... Among these ancillaries, the air supply circuit (oxygen) of the FC generator is particularly "greedy" in energy [5], [6]. It is classically carried out by a motor-compressor. Electrical conversion net efficiency of the energy brought by the $\mathrm{FC}$ is around $50 \%$ but up to $35 \%$ of the produced electrical energy is consumed by the ancillaries (among this part, the $2 / 3$ are consumed by the air supply). Thus, air supply system optimization is an important milestone on the road of efficient fuel cell systems (FCS). In this context, the aim of this paper is to propose an optimization of the motor-compressor by a deterministic (i.e., the CG) and stochastic (i.e., the PSO)

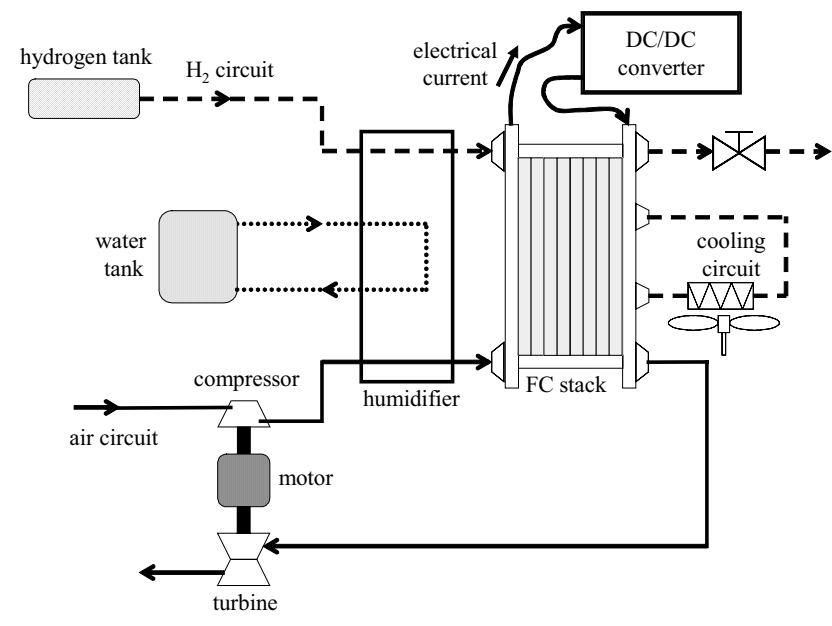

Fig. 1. Basic schema of FCS [5].

algorithm respectively, in order to compare both. The method consists in providing an optimization of the electrical motor based on efficiency/mass/efficiency-mass criterion [7], [8], [9], [10].

\section{Application Context}

The authors have chosen a realistic power of the FCS, which equals to $5 \mathrm{~kW}$. Indeed, a FCS of $5 \mathrm{~kW}$ is available at FCLAB Institute [Fig. 2.], so that the motor can be tested in real conditions. On the other hand, this power is compatible with the traction of a small vehicle, such as a scooter, or an Auxiliary Power Unit (APU) dedicated to automotive applications. Considering this level of power, the specifications of the machine are the following:

- maximal rotational speed: $10,000 \mathrm{rpm}$;

- mechanical power: 500W (at 10,000rpm);

- maximal electrical power: $1,000 \mathrm{~W}$ (lower than $20 \%$ of the FC power);

- efficiency at 500W and 10,000rpm: $\geq 91 \% \mathrm{~min}$.

Moreover, the design must be realistic in order to be embedded on a vehicle and to have an objective of series cost, if possible, compatible with the automobile applications. 


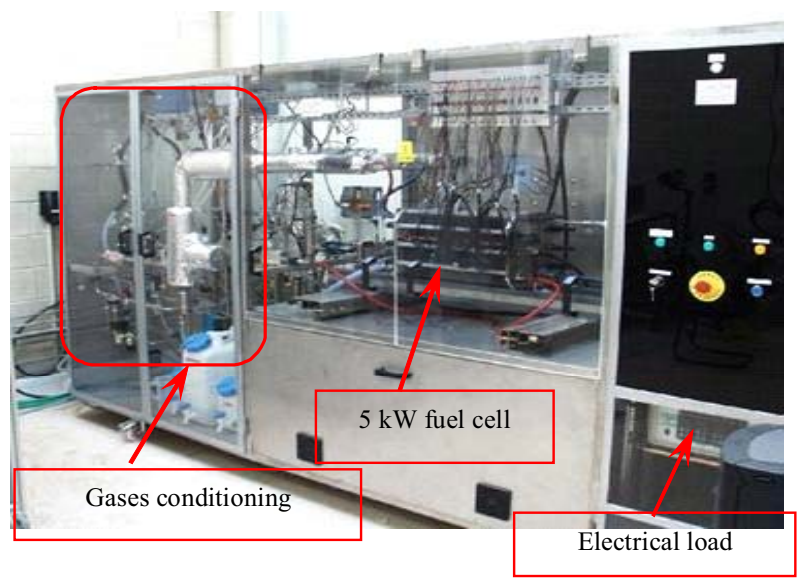

Fig. 2. 5kW FC test bench in the FC-LAB Institute.

\section{Design of the Electrical Machine}

In this section, the aim is not to describe the whole calculations of the motor design (already published in the thesis [11] and in the international publications [12], [13], [14]), but only to present the used design methodology and the PM motor optimizations for the drive of a FC air-compressor.

\section{A. Design Methodology}

The design methodology consists of five steps:

- The choice of the electrical machine type among the classical available technologies;

- The design of the stator (choice of the lamination material and winding);

- The design of the rotor (choice of the PM and rotor yoke materials, limits of PM height [12],...);

- The optimization of the whole geometrical parameters, by using a complete analytical model (AM), in order to find the best structure following the objective function (i.e., the efficiency/mass/efficiency-mass);

- The performances validations of the optimal machines by using a two-dimensional (2-D) numerical model (e.g., with finite element simulations).

The first three steps have been already detailed in [5]. The chosen internal rotor parallel-field PM motor has the following main characteristics:

- The lamination materials for the stator and rotor respectively: M 250-35 HA laminations and Id $35 \mathrm{~cd} 4$ (solid steel);

- The PMs are Nd-Fe-B magnets (N 30H with a parallel magnetization). Their magnetic characteristics are given in the TABLE I;

- The winding is an overlapping three-phased winding with two layers, a winding pitch $y_{w p}$ of $5 / 6$ (shortening step) and two slots per pole and per phase.

In this paper, only step four on the optimization of the whole geometrical parameters will be developed. It is made by using two optimization algorithms (i.e., CG and PSO), in order
TABLE I

Characteristics OF THE PMS

\begin{tabular}{lc}
\hline \hline Characteristics & Values \\
\hline Remanent flux density at $20^{\circ} \mathrm{C},[\mathrm{T}]$ & 1.13 \\
Coercitive magnetic field strength, $[\mathrm{kA} / \mathrm{m}]$ & -873.9 \\
Relative magnetic permeability, $[-]$ & 1.029 \\
Temperature coefficient of remanent flux density, $[\% / \mathrm{K}]$ & -0.12 \\
Temperature coefficient of magnetic field, $[\% / \mathrm{K}]$ & -0.6 \\
Electrical resistivity, $\left[10^{-6} \Omega \cdot m\right]$ & 1.44 \\
\hline \hline
\end{tabular}

to obtain the best geometrical parameters which successively satisfy the three following optimizations:

- to maximize efficiency $(\eta)$,

- to minimize mass $(M)$,

- to find a compromise between efficiency-mass $(\eta-M)$,

where $\eta$ is the efficiency of the machine (including copper losses, stator iron losses and mechanical losses) and $M$ is the mass of the machine.

Thereafter, a 2-D numerical validation of electrical machine (i.e., the step five of the design methodology) was realized on a efficiency criterion by CG (cf. IV-A.2).

Finally, the authors have chosen the lowest number of pole pairs (i.e., $p=1$ ). This chosen permits to limit the electrical frequency and, consequently, the iron losses $P_{\text {iron }}$ [5], [11]. It is clear that the specific power of the machine decreases with the number of pole pairs due to the increase of the section of the magnetic circuit, but, the main constraint of the studied application is to minimize the energy consumption and, for a high-speed machine, the iron losses are often the key component of the losses.

\section{B. Optimization of the Machine}

In order to achieve the optimization, the authors have developed a complete AM of the PM synchronous machine electromagnetic behaviour [11], [12], [13], [14]). This AM has two parts:

- the expressions of the whole magnetic variables by solving the Maxwell's equation in the air-gap, the PMs and the rotor yoke. Knowing the magnetic potential vector in three previous regions, it is possible to express the magnetic flux density in the whole motor, the back EMF and the electromagnetic torque...;

- a classical single-phased equivalent circuit of the PM synchronous machine which is, in fact, a representation of the power balance in the machine [Fig. 3.]. In this singlephased equivalent circuit, $V_{p h}$ and $I_{p h}$ are respectively the RMS values of the voltage and the current of one phase, $R_{p h}$ and $X_{p h}$ are respectively the resistance and the reactance of one phase, $E_{p h}$ is the RMS value of the back EMF and $R_{\text {iron }}$ a virtual resistance used to model the influence of the stator and rotor iron losses. In fact, this circuit makes it possible to express the losses and the efficiency, as well as $V_{p h}$ and $I_{p h}$. 


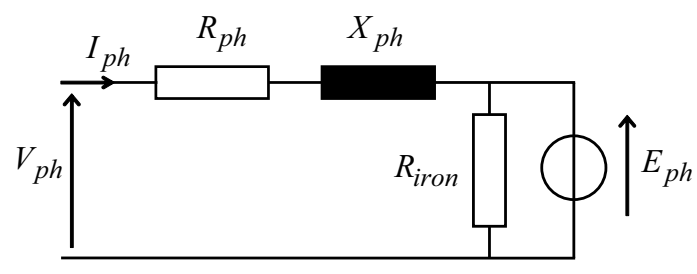

Fig. 3. Single-phased equivalent circuit of the motor.

Then, the problem of optimization has the following mathematical form:

- the optimization criteria:

$$
\left\{\begin{array}{l}
\mathbf{1}: \text { Max. } \eta\left(p g_{i}\right) \\
\mathbf{2}: \text { Min. } M\left(p g_{i}\right) \\
\mathbf{3}: \text { Compromise } \eta-M\left(p g_{i}\right)
\end{array},\right.
$$

- the optimization constraints:

$$
\left\{\begin{array}{l}
B_{s y} \leqslant 1.75[T] \\
B_{s t} \leqslant 1.75[T] \\
B_{r y} \leqslant 2.2[T] \\
V_{p h} \leqslant V_{p h_{\max }}=54 V \\
E_{p h}<V_{p h} \\
4 \leqslant J_{c d} \leqslant 8\left[\mathrm{~A} / \mathrm{mm}^{2}\right] \\
\tau_{r} \leqslant 35 \% \\
h_{m} \leqslant h_{m_{\max }}
\end{array},\right.
$$

- the exploration domain for each variable:

$$
\left\{\begin{array}{l}
1 \leqslant N_{s} \leqslant 25 \\
1 \leqslant N_{c w} \leqslant 10 \\
5 \leqslant \Theta_{t} \leqslant 25[\text { deg. }] \\
0 \leqslant \psi \leqslant 90[\text { deg. }] \\
0.5 \leqslant h_{s y} \leqslant 20[\mathrm{~mm}] \\
0.5 \leqslant h_{s t} \leqslant 50[\mathrm{~mm}] \\
0 \leqslant h_{r y} \leqslant 20[\mathrm{~mm}] \\
0 \leqslant h_{m} \leqslant 10[\mathrm{~mm}]
\end{array},\right.
$$

where $p g_{i}$ are the geometrical parameters; $B_{s y}, B_{s t}$ and $B_{r y}$ are respectively the flux density in the stator yoke, the stator teeth and the rotor yoke; $V_{p h_{\max }}$ is the maximal voltage of one phase; $J_{c d}$ is the current density in the slots; $h_{m}$ is the radial thickness of the PM; $h_{m_{\max }}$ is the maximal radial thickness of the PM which is defined in [12]; $\tau_{r}$ the fill factor in one slot; $N_{s}$ is the number of series turns per slot; $N_{c w}$ is the number of copper wire per turn; $\Theta_{t}$ is the mechanical angle of a stator tooth; $\psi$ is the difference of phase between the current and the back EMF; $h_{s y}, h_{s t}, h_{r y}$ and $h_{m}$ are respectively the height of the stator yoke, the stator teeth, the rotor yoke and the PMs.
TABLE II

Main Parameters of the Optimization by CG

\begin{tabular}{ccccc}
\hline \hline Criterion & $\mathbf{1}$ & & $\mathbf{2}$ & \\
Parameters & Parallel & Radial & Parallel & Radial \\
\hline$\eta,[\%]$ & $\mathbf{9 1 . 9 5}$ & $\mathbf{9 0 . 1 7}$ & 90.05 & 89.91 \\
$\mathrm{M},[\mathrm{kg}]$ & 2.59 & 2.3 & $\mathbf{1 . 2 8}$ & $\mathbf{1 . 2 7}$ \\
& & & & \\
$\mathrm{B}_{s y},[T]$ & 1.35 & 1.75 & 1.28 & 1.75 \\
$\mathrm{~B}_{s t},[T]$ & 1.35 & 1.18 & 1.67 & 1.42 \\
$\mathrm{~B}_{r y},[T]$ & 0.907 & 1.73 & 2.12 & 2.19 \\
$\mathrm{~V}_{p h},[V]$ & 47.9 & 42.82 & 20.86 & 20.35 \\
$\mathrm{E}_{p h},[V]$ & 46.63 & 41.65 & 20.82 & 20.1 \\
$\mathrm{~J}_{c d},\left[A / m m^{2}\right]$ & 4.22 & 4.72 & 6.08 & 7.78 \\
$\mathrm{I}_{p h},[A]$ & 3.58 & 4.01 & 8.59 & 8.79 \\
$\tau_{r},[\%]$ & 33.19 & 34.75 & 34.92 & 34.59 \\
$\mathrm{~h}_{m},[m m]$ & 5.14 & 4.77 & 1.29 & 1.58
\end{tabular}

\begin{tabular}{ccccc}
$\mathrm{N}_{s},[-]$ & 12 & 9 & 9 & 6 \\
$\mathrm{~N}_{c w},[-]$ & 3 & 3 & 5 & 4 \\
$\Theta_{t},[$ deg. $]$ & 20 & 20 & 9 & 12.07 \\
$\psi,[$ deg. $]$ & -2.77 & -2.49 & -21.32 & -19.45 \\
$\mathrm{~h}_{s y},[m m]$ & 13.5 & 13.5 & 7.93 & 9.9 \\
$\mathrm{~h}_{s t},[m m]$ & 17 & 14.03 & 9.95 & 6.71 \\
$\mathrm{~h}_{\text {ry }},[\mathrm{mm}]$ & 14 & 14.23 & 4.12 & 8.28 \\
& & & & \\
$\mathrm{R}_{\text {si }},[\mathrm{mm}]$ & 20 & 20 & 20 & 20 \\
$\mathrm{e},[\mathrm{mm}]$ & 1 & 1 & 1 & 1 \\
$\mathrm{R}_{c w},[\mathrm{~mm}]$ & 0.3 & 0.3 & 0.3 & 0.3 \\
$\mathrm{~B}_{g},[T]$ & 0.91 & 0.78 & 0.48 & 0.55 \\
$\mathrm{~T}_{\text {em }},[N m]$ & 0.48 & 0.48 & 0.48 & 0.48 \\
$\mathrm{P}_{j s},[W]$ & 14.58 & 14.51 & 37.13 & 31.09 \\
$\mathrm{P}_{\text {hyst }},[W]$ & 6.7 & 8.36 & 2.65 & 4.45 \\
$\mathrm{P}_{\text {fouc }},[W]$ & 18.96 & 23.67 & 7.5 & 12.59 \\
$\mathrm{P}_{\text {iron }},[W]$ & 25.66 & 32.03 & 10.146 & 17.04 \\
\hline
\end{tabular}

\section{Optimization RESUlts}

\section{A. Optimization by $C G$}

1) Method of CG: The optimization has been carried out by using the Mathcad software and a classical deterministic algorithm CG.

2) Optimization Results of CG: The optimization results for the efficiency and mass criterion are presented in the TABLE II. In this table, $R_{s i}$ represents the radius of the stator surface, $e$ the geometrical (actual) air-gap length, $R_{c w}$ the radius of copper wire, $B_{g}$ the magnetic flux density in the airgap, $T_{e m}$ the electromagnetic torque, $P_{j s}$ the copper losses, $P_{\text {hyst }}$ and $P_{\text {fouc }}$ respectively the iron losses by hysteresis and by eddy-currents. Due to the fact that optimization algorithm in Mathcad software does not handle multicriteria optimization, the optimization of efficiency-mass criterion is not currently done by $\mathrm{CG}$ optimization algorithm.

In this paper, a real electrical machine of optimization results is given. This optimization is realized on a efficiency criterion, i.e., Max. $\eta\left(p g_{i}\right)$, by CG. The Fig. 4. gives the photographs of the stator and the rotor of a prototype realized right to the results of the optimization. 




(a)

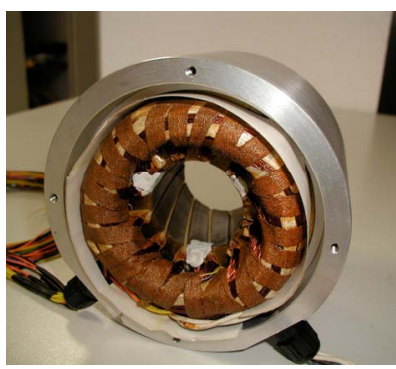

(b)
Fig. 4. Photographs of the realized prototype: (a) Rotor and (b) Stator.

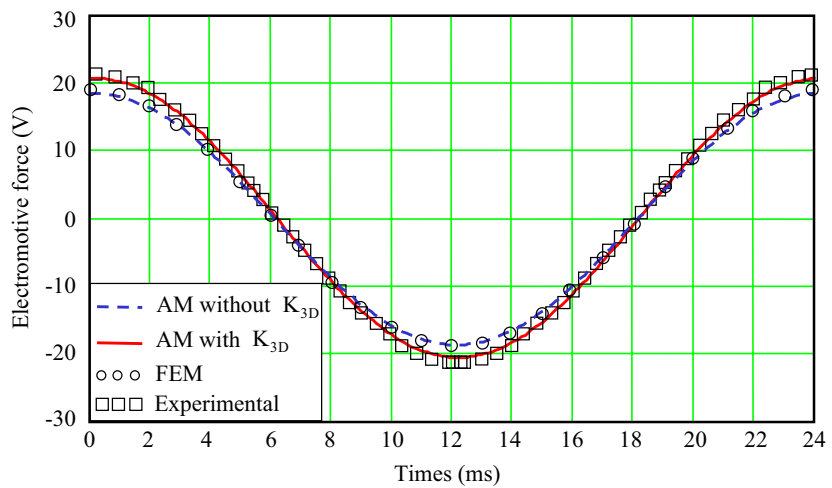

Fig. 5. Theoretical and experimental chronograms of the back EMF at 20C.

The back EMF of the machine has been measured at no-load generator mode at 20C. The results are plotted in Fig. 5. and compared with the results of 2-D finite element method (FEM) simulations and the ones of the AM. It is possible to observe discrepancies between the theoretical and experimental results. Then, the results of the AM have been corrected by using a factor, $K_{3 D}$, modeling the three-dimensional (3-D) endeffects [11], due to the fact that the PM length is higher than the stator length. This correction leads to an improvement of the agreement between theoretical and experimental results, proving the importance of the end-effects.

\section{B. Optimization by $P S O$}

\section{1) Method of PSO:}

a) Laws of PSO: PSO belongs to the broad class of stochastic optimization algorithms. The ideas that underlie PSO are not inspired by the evolutionary mechanisms encountered in natural selection, but rather by the social behaviour of flocking organisms, such as swarms of honeybees and fish shoals. It has been observed that the behaviour of the individuals that belong to a flock adheres to fundamental rules like nearest-neighbour velocity matching and acceleration by distance [15], [16]. PSO is a population-based algorithm that uses a population of individuals to probe promising regions of the search space. In this context, the population is called a swarm and the individuals are called particles. Each particle moves with an adaptable velocity within the search space [Fig. 6.], and keep in its memory the best position it ever

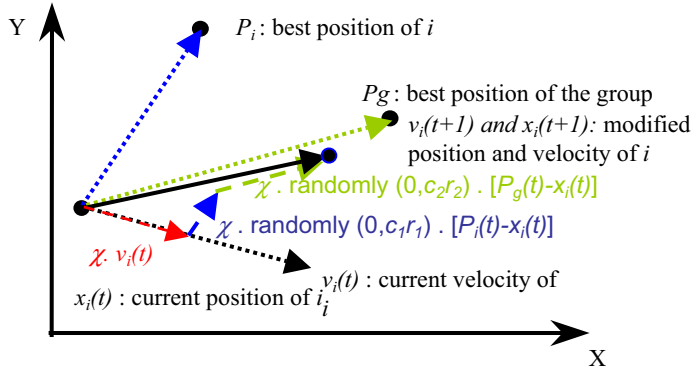

Fig. 6. Principle of the displacement of a particle in a 2-D space.

encountered. In the global variant of PSO the best position ever reached by all individuals of the swarm is communicated to the whole particles. In the local variant, each particle is assigned to a neighbourhood consisting of a specified number of particles. In this case, the best position ever reached by the particles that comprise the neighbourhood is communicated among them [17]. This paper considers the global variant of PSO only.

Let us assume a $D$-dimensional search space $S, S \subset \mathbb{R}^{D}$, and a swarm consisting of $\mathrm{N}$ particles. The $i^{\text {th }}$ particle is a $D$ dimensional vector has the following coordinates:

$$
X_{i}=\left(x_{i 1}, x_{i 2}, \ldots, x_{i D}\right)^{T} \in S,
$$

The velocity of this particle is also a $D$-dimensional vector such as:

$$
V_{i}=\left(v_{i 1}, v_{i 2}, \ldots, v_{i D}\right)^{T} \in S
$$

The best previous position encountered by the $i^{\text {th }}$ particle is a point in $S$, denoted as:

$$
P_{i}=\left(p_{i 1}, p_{i 2}, \ldots, p_{i D}\right)^{T} .
$$

If $g$ is the index of the particle that reached the best previous position among all the individuals of the swarm, and $t$ is the iteration counter. Then, according to the version of PSO, a parameter called the constriction factor is defined by Clerc et al. [18]. The swarm is thus manipulated according to the following equations:

$$
\begin{gathered}
V_{i}(t+1)=\chi \cdot\left\{\begin{array}{c}
V_{i}(t)+c_{1} \cdot r_{1} \cdot\left[P_{i}(t)-X_{i}(t)\right] \\
\ldots+c_{2} \cdot r_{2} \cdot\left[P_{g}(t)-X_{i}(t)\right]
\end{array}\right\}, \\
X_{i}(t+1)=X_{i}(t)+V_{i}(t+1),
\end{gathered}
$$

where $i=1,2, \ldots, N ; \chi$ is the constriction factor; $c_{1}$ and $c_{2}$ (with experimental value of 2.5) denote the cognitive and social parameters respectively; and $r_{1}$ and $r_{2}$ are random numbers uniformly distributed in the interval $[0,1]$. The value of the constriction factor is typically obtained through the formula [18]:

$$
\chi=\mid \begin{array}{ll}
\frac{2 \cdot \kappa}{\phi-2+\sqrt{\phi^{2}-4 \cdot \phi}} & \text { for } \phi>4 \\
\sqrt{\kappa} \quad \text { for } \phi \leqslant 4
\end{array},
$$

with $\kappa=1$ and $\phi=c_{1} \cdot r_{1}+c_{2} \cdot r_{2}$. 
b) Constraint Handling of PSO: Several studies are reported in the literature that extended PSO to constrained optimization problems and various constraint handling techniques were used [19], [20].

Here, a method inspire to [21] is used to solve constrained optimization problems. The preserving feasibility strategy is implemented to deal with constraints. Two modifications of the PSO algorithms have been proposed:

- When updating the memories pbest (coordinate of best fitness value of each particles) and gbest (coordinate of best fitness value of all particles), each particle only keep feasible solutions in its memory and leave aside other solutions that are not respecting imposed constraints;

- During the initialization process, one particle, at least, is started with feasible solution.

Compared to other constraint handling techniques, this approach has the following advantages:

- It is quite simple. There is no pre-processing to the constraints and there is neither complicated manipulation. Fitness function and constraints are handled separately, thus there are no limitations to the constraints;

- It is faster. The only part of the algorithm dealing with constraints is to check if a solution satisfies all the constraints. This will reduce the computation time when handling multiple or complicated constraints.

c) Optimization Process of PSO: The implementation of PSO program is easy and only takes a few lines. For example, in our case, the algorithm is programmed in Mathcad software and only takes twenty-five lines. More precisely the different steps of the PSO program are described in Fig. 7.

Firstly, for this model, the PSO algorithm generates motor construction parameters. In the second step, the model is simulated. The third step consists in simulation result evaluation in order to define the value of optimization objective function. Finally, a new set of optimization parameters is evaluated.

In this paper a complementary function, introduces in [21], is used. It's dispatching function. It allows decreasing the optimization time and reducing the probabilities of being blocked in a minimum local. This function disperses randomly in search space the particles when the majority of them are in an hypersphere dimension $R$ (another variable).

2) Optimization Results of PSO: In PSO case, all optimizations are based on 3000 iterations and 20 particles. According to numerous papers and our experience, the choice of 20 particles is suitable for a wide number of optimization processes. Stochastic optimization methods ensure finding the global optimum with an infinite time of optimization what is not really conceivable. The choice of 3000 iterations is based on our own simulation know how and on the constraint to have a reasonable computational time.

Let us have a look at the optimization progress [cf. Figs. 8]. On the Fig. 8(a), the progress (during iterations) of the state of particles is provided. The particles respecting all the imposed constraints are entered as good particles. We can observe the increase in the number of good particles with the increase

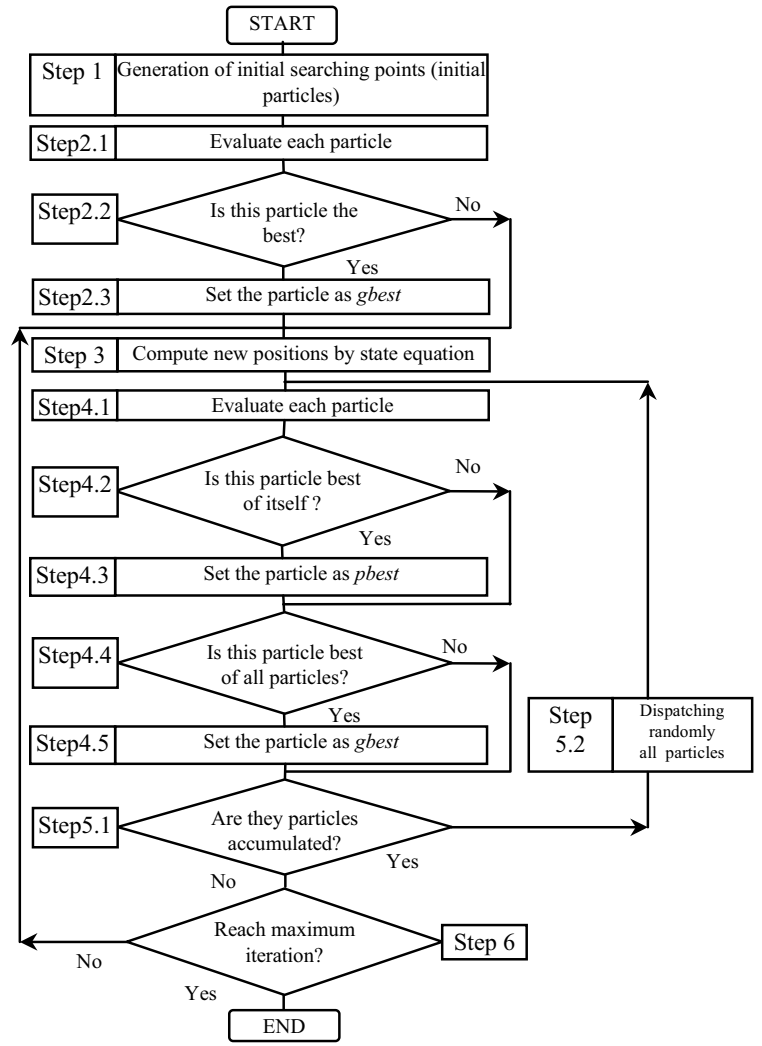

Fig. 7. Flow chart of optimization process by PSO.

in the iteration count. Reaching a certain iteration count we see a sudden fall of the number of good particles which can be explained by the process of dispatching (i.e., when the particles are in a hypersphere dimension $R$ ), they are dispersed randomly in search space. That is a complementary function making it possible to decrease the probabilities of being blocked in a local minimum. In fact, it allows decreasing blocking time because, in absolute, a stochastic algorithm must to find the global optimum.

The Fig. 8(b) provides the evolution of the objective function which begins with a value of 0 and stops with a value of 2 that corresponds to the objective function obtained for an optimization on efficiency/mass compromise criterion with magnets radial magnetized. The value 2 corresponds an efficiency of $90.25 \%$ and a mass of $1.35 \mathrm{~kg}$. The objective function evolution becomes very slow after 600 iterations. Furthermore, particles are 3 times redistributed between iteration 1900 and iteration 2700. It is thus possible to say it is at least a local optimum. The same process is used to optimize the PM motor in using radial and parallel magnetized magnet and in using optimizations criterions such as efficiency/mass/efficiency-mass. The all optimization variables and results are presented in the TABLE III.

Results are used to see that the PSO tends to the optimum. If one look carefully all results filling ratio tend to the maximum. The current density $J_{c d}$ in the slots, the magnetic flux density $B_{s y}, B_{s t}$ and $B_{r y}$ tend to the maximum for mass optimizing. 


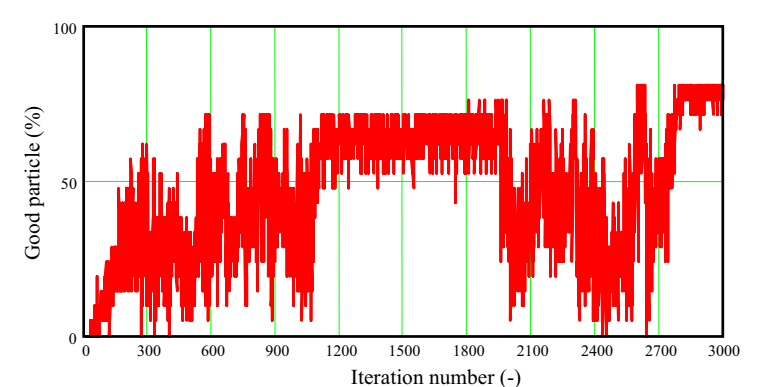

(a)

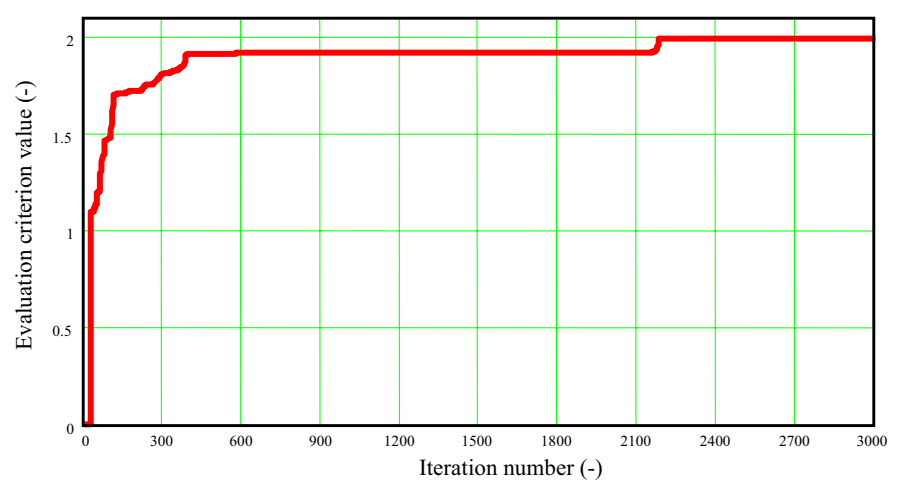

(b)

Fig. 8. Evolution of (a) good particles percentage and (b) objective function during optimization.

All these logic indicator reflects the optimum effectiveness of the PSO.

\section{Comparison between $C G$ and PSO Performance}

In these histograms, which are represented in the Figs. 9, the authors show the global efficiency and the mass of PSO compared to CG even if time of simulation is more long. After many simulation, the authors note that $\mathrm{CG}$ is often blocked in a local minimum. Moreover, our experience make it possible to say that, for constraint handling, CG need to hard constraint such as equality in order to converge. While PSO finds solution easily when its constraints are constraints of inequality. The equality constraints limit strongly exploration domain of particles because of taking in account of constraint handling.

In summary, each algorithm has its advantages and drawbacks. The requirement of the application will guide the choice of algorithm optimization. The predilection fields of PSO are:

- Non-linear model,

- Multi-criteria optimization,

- Use of discrete variables,

- Global optimization.

Nevertheless, the CG has a major asset which is the execution time for the linear models.

\section{CONClusion}

In this paper, the authors have presented the optimization comparison of a PM synchronous motor for FC ancillaries
TABLE III

MAIN PARAMETERS OF THE OPTIMIZATION B Y PSO

\begin{tabular}{|c|c|c|c|c|c|c|}
\hline Criterion & 1 & & 2 & & 3 & \\
\hline Parameters & Parallel & Radial & Parallel & Radial & Parallel & Radia \\
\hline$\eta,[\%]$ & 93.29 & 93.19 & 88.07 & 88.84 & 89.64 & 90.25 \\
\hline $\mathrm{M},[\mathrm{kg}]$ & 3.39 & 2.99 & 0.98 & 1.12 & 0.99 & 1.35 \\
\hline $\mathrm{B}_{s y},[T]$ & 0.54 & 0.8 & 1.75 & 1.75 & 1.75 & 1.75 \\
\hline $\mathbf{B}_{s t},[T]$ & 1.56 & 1.75 & 1.75 & 1.37 & 1.75 & 1.29 \\
\hline $\mathrm{B}_{r y},[T]$ & 0.72 & 1.27 & 1.73 & 2.2 & 2.2 & 2.2 \\
\hline $\mathrm{V}_{p h},[V]$ & 25.4 & 23.9 & 16.2 & 13.3 & 26.39 & 15.54 \\
\hline $\mathrm{E}_{p h},[V]$ & 24.88 & 23.31 & 16.08 & 13.12 & 25.17 & 14.84 \\
\hline $\mathrm{J}_{c d},\left[A / \mathrm{mm}^{2}\right]$ & 4 & 4.23 & 8 & 8 & 8 & 8 \\
\hline $\mathrm{I}_{p h},[A]$ & 6.79 & 7.17 & 11.31 & 13.57 & 6.79 & 11.31 \\
\hline$\tau_{r},[\%]$ & 35 & 35 & 35 & 35 & 35 & 35 \\
\hline $\mathrm{h}_{m},[m m]$ & 2.04 & 2.46 & 1.29 & 1.05 & 1.76 & 1.86 \\
\hline $\mathrm{N}_{s},[-]$ & 8 & 6 & 7 & 5 & 9 & 4 \\
\hline $\mathrm{N}_{c w},[-]$ & 6 & 6 & 5 & 6 & 3 & 5 \\
\hline$\Theta_{t},[$ deg. $]$ & 12.77 & 11.32 & 8.5 & 9.86 & 10.59 & 14.64 \\
\hline$\psi,[$ deg. $]$ & -9.24 & -4.59 & -23.62 & -20.59 & -12.63 & -6.72 \\
\hline $\mathrm{h}_{s y},[\mathrm{~mm}]$ & 25 & 25 & 5.73 & 7.82 & 6.96 & 10.94 \\
\hline $\mathrm{h}_{s t},[\mathrm{~mm}]$ & 12.32 & 9.09 & 7.87 & 7.29 & 6.87 & 6.48 \\
\hline $\mathrm{h}_{r y},[m m]$ & 15.5 & 16.54 & 4.99 & 6.54 & 4.68 & 9.11 \\
\hline $\mathrm{R}_{s i},[\mathrm{~mm}]$ & 20 & 20 & 20 & 20 & 20 & 20 \\
\hline $\mathrm{e},[\mathrm{mm}]$ & 1 & 1 & 1 & 1 & 1 & 1 \\
\hline $\mathbf{R}_{c w},[m m]$ & 0.3 & 0.3 & 0.3 & 0.3 & 0.3 & 0.3 \\
\hline $\mathrm{B}_{g},[T]$ & 0.66 & 0.64 & 0.48 & 0.43 & 0.59 & 0.62 \\
\hline $\mathrm{T}_{e m},[N m]$ & 0.48 & 0.48 & 0.48 & 0.48 & 0.48 & 0.48 \\
\hline $\mathrm{P}_{j s},[W]$ & 17.69 & 14.22 & 48.71 & 41.44 & 37.1 & 27.34 \\
\hline $\mathrm{P}_{\text {hyst }},[W]$ & 2.67 & 3.74 & 2.87 & 3.49 & 3.32 & 4.88 \\
\hline $\mathrm{P}_{\text {fouc }},[W]$ & 7.57 & 10.60 & 8.14 & 9.89 & 9.4 & 13.82 \\
\hline $\mathrm{P}_{\text {iron }},[W]$ & 10.25 & 14.34 & 11.01 & 13.38 & 12.72 & 18.71 \\
\hline
\end{tabular}

with two different algorithms: CG and PSO. The considered level of mechanical power is $500 \mathrm{~W}$ for the motor, which is the necessary power for a $5 \mathrm{~kW}$ FCS.

The optimizations are carrying out on three different objective functions (i.e., efficiency/mass/efficiency-mass). The results allow to compare the both algorithms and to deduce their advantages and drawbacks.

The first experimental and numerical results seem to validate the computations. Now, after the full tests, the next target is to realize the better adapted motor and to couple it with a real compressor and to test it at the FC-LAB Institute with a real FCS.

\section{REFERENCES}

[1] J. Milliken, F. Joseck, M. Wang, and E. Yuzuguhu, "The Advanced Energy Initiative," Journal of Power Sources, Vol. 171, no. 1, pp. 121131, Oct. 2007.

[2] M. Purman, and Z. Styczynski, "Power Flow Investigation of a PEM Fuel Cell System," in Proc. IEEE Power Engineering Society, Vol. 1, pp. 399-404, 7-12 Sep. 2003.

[3] P. Rodatz, G. Paganelli, and L. Guella, "Optimizing Air Supply Control of a PEM Fuel Cell System," in Proc. American Control, Vol. 3, pp. 2043-2048, 4-6 June 2003. 


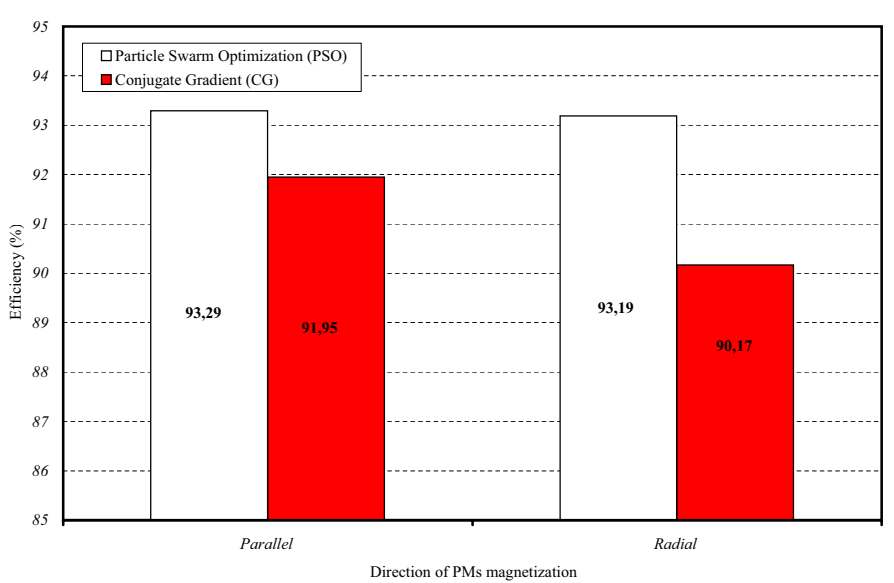

(a)

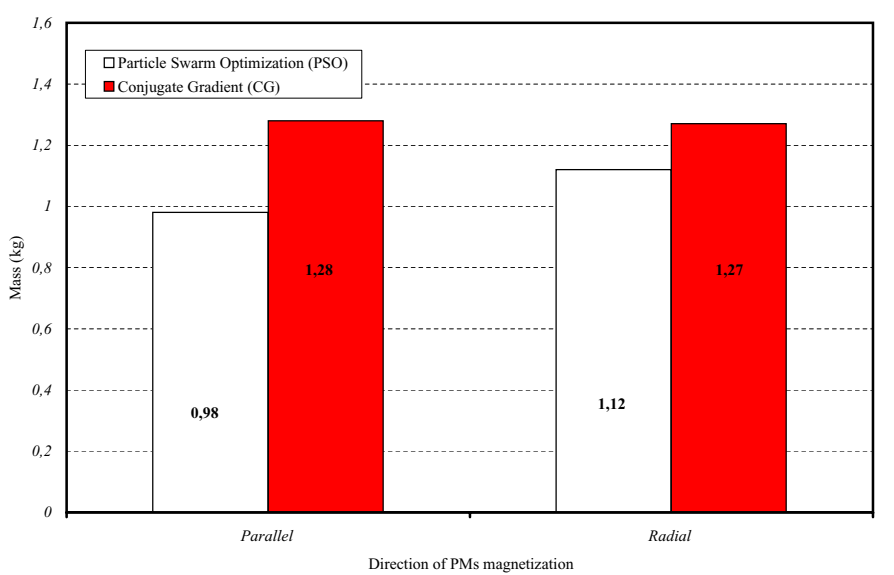

(b)

Fig. 9. Comparison between CG and PSO: (a) Efficiency and (b) Mass.

[4] J.T. Pukrushpan, A.G. Stefanopoulou, and H. Peng, "Control of fuel Cell Breathing," IEEE Control Systems Magazine, Vol. 24, no. 2, pp. 30-46, 4-6 April 2003.

[5] F. Dubas, C. Espanet, and A. Miraoui, "Design of a High-speed Permanent Magnet Motor for the Drive of a Fuel Cell Air Compressor," in Proc. IEEE Vehicular Power and Propulsion, pp. 603-610, 07-09 Sep. 2005. (Prize Paper Award from the IEEE VPPC'05).

[6] M. Tekin, D. Hissel, M.C. Pera, and J.M. Kauffmann, ”Energy Comsumption Reduction of a PEM Fuel Cell Motor-compressor Group Thanks to Efficient Control Laws", Journal of Powers Sources, Vol. 156, no. 1, pp. 57-63, May 2003.

[7] C. Ou, and W. Lin, "Comparison between PSO and GA for Parameters Optimization of PID Controller," in Proc. IEEE Mechantronics and Automation, pp. 2471-2475, 25-28 June 2006.

[8] K. Preis, O. Biro, M. Friedrich, A. Gottvald, and C. Magele, "Comparison of Different Optimization Strategies in the Desing of Electromagnetic Devices," IEEE Trans. on Magn., Vol. 27, no. 5, pp. 4154-4157, Sep. 1991.

[9] V.Z. Sadegh, and A.H. Isfahani, "Multiobjective Design Optimization of Air-core Linear Permanent-Magnet Synchronous Motors for Improved Thrust and Low Magnet Consumption," IEEE Trans. on Magn., Vol. 42, no. 3, pp. 446-452, March 2006.

[10] J. Azzouzi, R. Abdel-Karim, N. Barakat, R. Belfkira, and B. Dakyo, "Design Optimization of an Axial Flux PM Synchronous Machine: Comparison between DIRECT Method and GAs Method," in Proc. IEEE Power Electronics and Motion Control, pp. 1094-1098, August 2006.

[11] F. Dubas, "Conception d'un moteur rapide aimants permanents pour l'entranement de compresseurs de piles combustible," Ph.D. disserta- tion, Electrical Engineering and Systems (LEES), University of FrancheComte (UFC), Belfort, France, 2006.

[12] F. Dubas, C. Espanet, and A. Miraoui, "An Original Analytical Expression of the Maximum Magnet Thickness in Surface Mounted Permanent Magnet Motors," Eur. Phys. J. Appl. Phys. (EPJAP), Vol. 38, no. 2, pp. 169-176, May 2007.

[13] F. Dubas, C. Espanet, and A. Miraoui, "Field Diffusion Equation in High-Speed Surface Mounted Permanent Magnet Motors, Parastic Eddy-Current Losses," in CdRom ELECTROMOTION, pp. 01-06, 2729 September 2005.

[14] F. Dubas, and C. Espanet, "Exact Analytical Model of the No-Load Flux Density in the Air-gap, the Permanent Magnets and the Rotor Yoke for the Surface Mounted Permanent Magnet Motors," Int. Review of Elec. Eng. (IREE), Vol. 2, no. 3, pp. 425-437, May/June 2007.

[15] R.C. Eberhart, P. Simpson, and R. Dobbins, "Computational Intelligence PC Tools," 1st ed. Boston, MA: Academic Press Professional, New York: Academic, 1996.

[16] J. Kennedy, and R.C. Eberhart, "Particle Swarm Optimization," in Proc. IEEE Neural Networks, Vol. 4, pp. 1942-1948, Nov./Dec. 1995.

[17] P.N. Suganthan, "Particle Swarm Optimiser with Neighbourhood Operator," in Proc. IEEE Int. Congr. Evol. Comput., Department of Computer Science and Electrical Engineering, Vol. 3, pp. 1958-1962, 6-9 July 1999.

[18] M. Clerc, and J. Kennedy, "The Particle Swarm-Explosion, Stability, and Convergence in a Multidimensional Complex Space", IEEE Trans. Evol. Comput., Vol. 6, pp. 58-73, Feb. 2002.

[19] K.E. Parsopoulus, and M.N. Vrahatis,"Particle Swarm Optimization Method for Constrained Optimization Problems," in Proc. Eurointernational Symposium on Computational intelligence, 2002.

[20] T. Ray, and K.M. Liew, "A Swarm with an Effective Information Sharing Mechanism for Unconstrained and Constrained Single Objective Optimization Problem," in Proc. IEEE Conference on Evol. Comp., Vol. 1, pp. 75-80, May 2001.

[21] A. Sari, C. Espanet, and D. Hissel, "Particle Swarm Optimization Applied to the Co-design of a Fuel Cell Air Circuit," Journal of Power Sources, Vol. 179, no. 1, pp. 121-131, April 2008. 